DOI https://doi.org/10.30525/978-9934-26-008-7.1-9

\title{
STOCHASTIC MODELING OF ELECTRICAL SYSTEMS OF PRODUCTION STRUCTURES OF INDUSTRIAL ENTERPRISES
}

\author{
Kuznetsov V. V., Tryputen M. M.
}

\section{INTRODUCTION}

Workshops of industrial enterprises often use powerful consumers, distorting shape and disturbing voltage symmetry in workshop power grid, in one grid with asynchronous motor (AM). Reduced quality of power voltage results in pulsation of the moment generated by the motor, drop of starting and critical AM moment, increase in vibration, early wear of bearing and gear components, increased steel losses due to higher harmonic field constituents in a gap, reduction in such power indices of asynchronous motor operation as efficiency coefficient and power coefficient. Early evaluation of power quality indices and provision of adequate modes of electric equipment operation under specific conditions is essential research and practice problem.

The problem solution involves a number of experiments under the conditions of different power quality indices, different modes of electric equipment operation, and different means to protect the latter from noisy power. However, such experiments carried out in the context of a real object would result in: significant time consumption because of the necessity to wait for such situations when energy within power grids corresponds to the required quality indices without mentioning losses of electric equipment life; financial expenditures due to the necessity to purchase various high-priced devices to protect the electric facilities and to rehabilitate electric energy within the grids; and accident threat due to the decreased reliability indices of electric facilities operating under the considered conditions.

Computational studies, based upon the development of simulation system as well as upon statistical tests by computers, helps accelerate and simplify considerably the process of the experiments. The method differs from standard experimental ones in the fact that simulation model, implemented by a computer, is analyzed rather than the object itself. In this context, interaction with the former is performed just as it 
was done with a prototype system and simulation results are processed and tested in such a way as if they were data of full-scale experiments ${ }^{1}$.

Relying upon features of asynchronous motor (AM) functioning within noisy power grid, its electromagnetic model should be completed with a subsystem imitating random changes in electrical energy quality. The latter may be implemented with the help of generation of linear voltage within workshop power grids as well as with the help of the indices calculation.

\section{Stochastic model of random voltage changes in the electrical system of an industrial enterprise}

Direct simulation of linear voltage within a grid with noisy electricity is complicated by the fact that all harmonic components have fixed frequencies of their oscillations; only random changes in amplitudes and initial phases are superimposed on them. In this contest, further analysis of AM energy data in terms of its mathematical model involves preliminary decomposition of the voltages into the components. It follows that it is more expedient to generate amplitudes and initial phases of available harmonics, which statistical regularities of changes should be obtained previously, rather than the random voltage sequences ${ }^{2}$.

Fig. 1 represents one of the potential variations of the generator of random changes in linear voltages taking into consideration the mentioned above ${ }^{3}$.

In this context, $\Gamma_{\gamma}$ is generator of "white" noise (i.e. values of uniformly distributed uncorrelated random value corresponding to time moments $\Delta \mathrm{t}_{\gamma}$ within $0 ; 1$ interval); $\Pi_{U_{m A B i \gamma}}$, and $\Pi_{U_{m B C i \gamma}}$ are converters of amplitude distribution laws $i=\overline{1, n}$ - harmonics of linear voltages $\mathrm{U}_{\mathrm{mAB}}$ and $\mathrm{U}_{\mathrm{mBC}}$ respectively; $\Pi_{\Psi_{\mathrm{ABi}}}$, and $\Pi_{\Psi_{\mathrm{BC} i \mathrm{r}}}$ are converters of the initial phase distribution laws $i=\overline{1, n}$ - harmonics of the listed voltages $\mathrm{U}_{\mathrm{AB}}$,

${ }^{1}$ Строгалев В.П. Имитационное моделирование : учеб. пособие. Москва : Изд-во МГТУ им. Н.Э. Баумана, 2008. 280 с.

2 Качан Ю.Г. О моделировании напряжений в электрических сетях промышленных предприятий. Електротехніка $i$ електроенергетика. № 1. 2012. C. 72-75.

${ }^{3}$ M. Tryputen, V. Kuznetsov, A. Kuznetsova, K. Maksim and M. Tryputen, Developing Stochastic Model of a Workshop Power Grid, 2020 IEEE Problems of Automated Electrodrive. Theory and Practice (PAEP), Kremenchuk, Ukraine, 2020, pp. 1-6, doi: 10.1109/PAEP49887.2020.9240898. 
and $\mathrm{U}_{\mathrm{BC}} ; \Phi_{U_{m A B i \gamma}}$, and $\Phi_{U_{m B C i \gamma}}$ are filters generating the correlated amplitudes of harmonics of linear voltages $\mathrm{U}_{\mathrm{AB}}$, and $\mathrm{U}_{\mathrm{BC}}$ respectively; $\Phi_{\Psi_{A B i}}$, and $\Phi_{\Psi_{B C C_{Y}}}$ are filters generating the correlated initial phases of harmonics of the same voltages; $\tau_{\left(U_{m A B} \rightarrow U_{m B C}\right)}$ is amplitude shift of $i^{\text {th }}$ harmonic of linear voltage $\mathrm{U}_{\mathrm{BC}}$ relative to linear voltage $\mathrm{U}_{\mathrm{AB}}$ along the $\tau$ axis being determined on their cross-correlation function; and $\tau_{\left(\Psi_{A B} \rightarrow \Psi_{B C}\right) i}$ is a shift of the initial phase of $i^{t \text { th }}$ harmonic of linear voltage $\mathrm{U}_{\mathrm{BC}}$ relative to the initial phase of $i^{\text {th }}$ harmonic of linear voltage $\mathrm{U}_{\mathrm{AB}}$ along the $\tau$ axis being determined on their cross-correlation function.

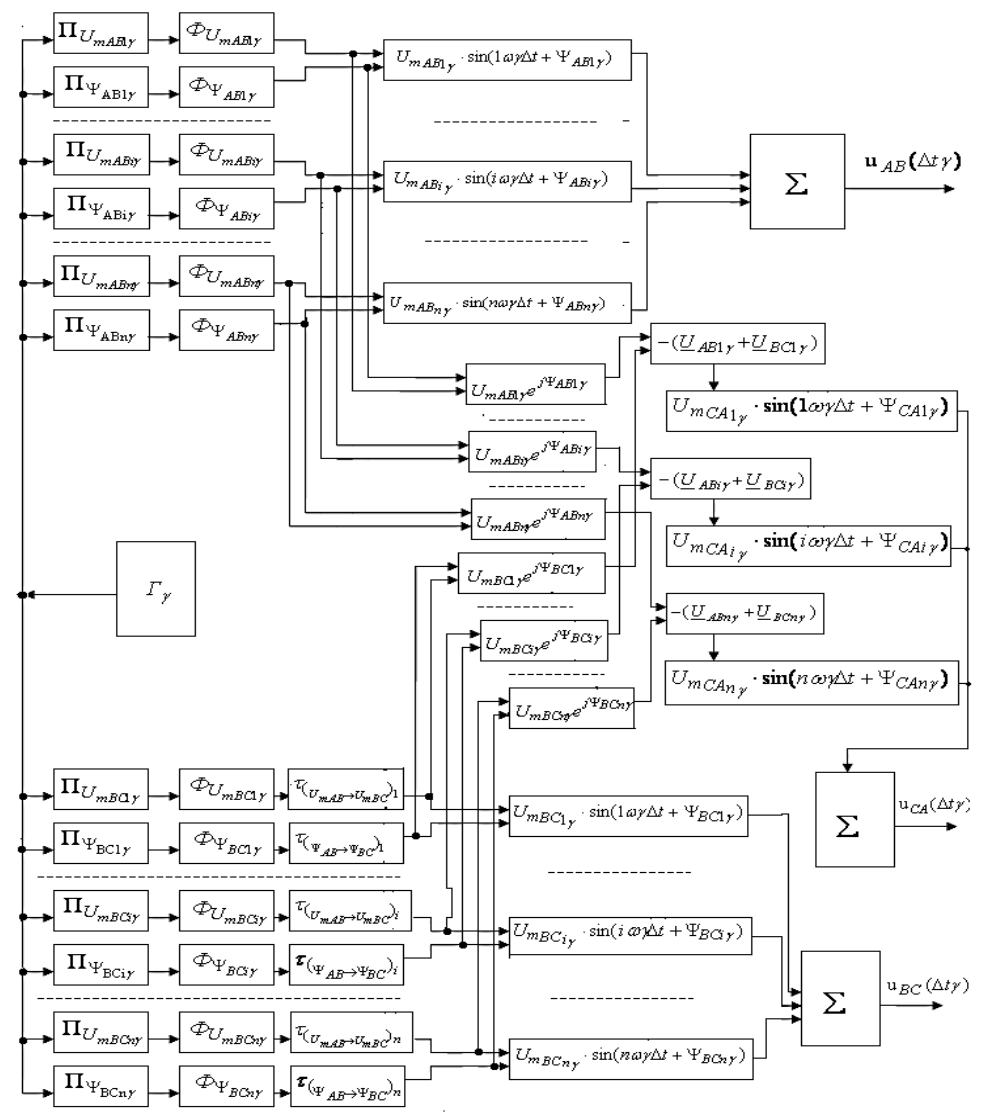

Fig. 1. Generator of linear voltages 
According to random changes in amplitudes $\left(\mathrm{U}_{\mathrm{mABi}}, \mathrm{U}_{\mathrm{mBCi}}, \mathrm{U}_{\mathrm{mCAi}}\right)$, and initial phases $\left(\psi_{A B i}, \psi_{B C i}, \psi_{C A i}\right)$ of harmonic components of linear voltages, simulated in such a way, their instantaneous values are determined. Then the latter are added algebraically in summators forming random sequences $\mathrm{u}_{\mathrm{AB}}(\Delta \mathrm{t} \gamma), \mathrm{u}_{\mathrm{BC}}(\Delta \mathrm{t} \gamma)$, and $\mathrm{u}_{\mathrm{CA}}\left(\Delta \mathrm{t}_{\gamma}\right)$.

As it is seen from Fig. 1, initial random process, being a random uncorrelated value, distributed on uniform laws within [0;1] interval, is simulated by corresponding generator. There are different techniques to obtain it; however, to all practical purposes, program method to generate pseudorandom sequences (PRS) is the most convenient in this context. In their software, the current computers have built-in function to generate PRSs helping them solve the majority of problems of signal simulation.

$\Pi_{U_{m A B i}}, \Pi_{U_{m B C i y}}$, and $\Pi_{\Psi_{A B i y}}, \Pi_{\Psi_{B C i y}}$ units transform initial random signal to those uncorrelated ones predetermined distribution laws. Selection of the most efficient signal depends upon the type of the laws. Nonlinear transformation methods (i.e. inverse function), piecewiselinear approximation of distribution law, and a method of elimination (by Neumann) are mostly used to perform the operation ${ }^{4}$.

Generating filters $\Phi_{U_{m A B i \gamma}}, \Phi_{U_{m B C C_{\gamma}}}, \quad \Phi_{\Psi_{A B i_{\gamma}}}$, and $\Phi_{\Psi_{B C i \gamma}}$ transform uncorrelated random sequences with the predetermined distribution laws into the correlated ones according to autocorrelation functions of the considered values. Nonrecursive filtration of input sequence is one of the most popular transformation techniques ${ }^{5}$ :

$$
y_{n}=\sum_{k=0}^{N} S_{k} x_{n-k},
$$

where $\mathrm{M}\left[y_{n}\right]=0$, and

$$
\mathrm{M}\left[y_{n} y_{k}\right]=\left\{\begin{array}{l}
\mathrm{K}_{n-k},|n-k| \leq \mathrm{N} ; \\
0,|n-k|>\mathrm{N},
\end{array}\right.
$$

where $\mathrm{y}_{\mathrm{n}}-$ is output correlated sequence, $x_{n}$ is input uncorrelated sequence, $S_{k} \mathrm{~S}_{\mathrm{K}} \mathrm{c}_{\mathrm{k}}$ are coefficients, $\mathrm{K}_{n-k} \mathrm{~K}_{\mathrm{n}-\mathrm{k}}$ is a value of correlation function within $\mathrm{n}-\mathrm{k}) \Delta$ point, and $\mathrm{M}$ is expectation symbol.

4 Прохоров С.А. Математическое описание и моделирование случайных процессов. Уральск : Самар. гос. аэрокосм. ун-т, 2001. 209 с.

${ }^{5}$ Yaglom, A.M. Correlation Theory of Stationary and Related Random Functions : Supplementary Notes and References. (Springer Series in Statistics). Softcover reprint of the original 1st ed. 1987 edition. 287 p., Springer, New York; (October 13, 2011). 
Random change in linear voltage $\mathrm{U}_{\mathrm{BC}}$ results from its crosscorrelation function with $\mathrm{U}_{\mathrm{AB}}$ voltage. $\varphi_{\mathrm{AB}, \mathrm{i}}$ (междуфазами $\left.\mathrm{U}_{\mathrm{Ai}} \mathrm{n} \mathrm{U}_{\mathrm{Bi}}\right)$. $\varphi_{\mathrm{AB}, \mathrm{i}}$ (междуфазамиU $\mathrm{U}_{\mathrm{Ai}} и \mathrm{U}_{\mathrm{Bi}}$ ). The simplest technique to solve the problem is in PRS generation with the prescribed type of a correlation function, and its corresponding time interval delay. The fact can explain availability of $\tau_{\left(U_{M A B} \rightarrow U_{M B C}\right) i}$ and $\tau_{\left(\Psi_{A B} \rightarrow \Psi_{B C}\right) i}$ units within the structural circuit. Instantaneous value of linear voltage $\mathrm{u}_{\mathrm{CA}}(\mathrm{t})$ is determined according to the known ratio:

$$
\underline{U}_{C A}=-\left(\underline{U}_{A B}+\underline{U}_{B C}\right) \text {. }
$$

It is clear that (2) dependence use will result in the formation of systematic error since values of linear voltage $\underline{\mathrm{U}}_{\mathrm{CA}}$ will not correspond to a distribution law being typical for it. It is possible to eliminate the error while implementing randomly selected sequence (i.e. randomization) of linear voltage generation.

\section{Identification of statistical models of the electrical system of the production structure of an industrial enterprise}

As stated above, the use of statistical modeling technique to simulate linear voltages within a workshop power grid with the help of a computer, involves availability of information concerning statistical regularities of values being modeled. Obtaining of the latter is connected with the analysis of random processes, i.e. time functions which can be obtained on the basis of passive industrial experiments.

Currently, the required data are recorded by means of digital controlling devices generating random sequence with $\Delta t$ discreteness from a continuous signal. Such a transformation may result in so-called frequency masking and, as a consequence, in the distortion of the signal statistical characteristics. Hence, to avoid the masking errors, initial signal should be passed through low-frequency filter while linear voltage recording in the context of a certain workshop.

Parameters of the filter are selected basing upon following assumptions. If the recordable analogue linear voltages should be digitalized for their further analysis (for instance, over a range of $\mathrm{f}_{\min }=0-\mathrm{f}_{\mathrm{H}}=0 \mathrm{f}_{\max }=2000 \mathrm{f}_{\mathrm{B}}=2000 \mathrm{~Hz}$ ), then filter frequency is to be determined in accordance with ${ }^{6}$ expression:

6 Бендат Дж. Прикладной анализ случайных данных. Москва : Мир, 1989. $540 \mathrm{c.}$ 


$$
f_{n f}=\frac{f_{\max }}{0.8}=\frac{2000}{0.8}=2500 \mathrm{~Hz} .
$$

Hence, the required discreteness interval $\Delta t$ is:

$$
\Delta t=\frac{1}{2 f_{n f}}=\frac{1}{2 \times 2500}=2 \times 10^{-4} \mathrm{~s} .
$$

While quantizing the analogous signal on a level, it is required to provide its ratio to mean-square noise intensity being no less than $80 \mathrm{~dB}$ (i.e. $10^{4}$ on amplitude) $10^{4}$ поамплитуде). That can be achieved, if following condition is fulfilled:

$$
\frac{2^{n}}{0.289}=10^{4}
$$

where $\mathrm{n}$ is the number of bits per one counting.

While taking the base-10 logarithm of both sides of the equation, we obtain $0.301 \mathrm{n}=3.46$, i.e. $n=11.5 \mathrm{n}=11,5 \mathrm{n}=11,5$. Thus, 12 is the number of bits required to quantize analogue signal per one counting. Among all the available industrial detectors, such a device as SCPED (i.e. a system to control parameters of electric drives) by RPE Center for Electromechanical Diagnostics Ltd transforms analogue signal with the prescribed signal/noise ratio.

During industrial experiment, carried out in the context of rolling plant 1 of Dneprospetsstal OJSC (Zaporozhie), implementations of random sequences of linear voltages with 22-24 hour duration were obtained. Initial stage of such random sequences should determine their classification. The procedure makes it possible to identify the process kind (i.e. steady-flow or transient one); its type (i.e. additive, multiplicative, or additive-multiplicative one); as well as a type of a deterministic component (i.e. linear, exponential, repetitive, or repetitive extinction process).

Correct classification determines broadly reasonableness of further statistical processing; as a rule, it is identified according to a scheme represented in fig. 2.

In this context: ME is mathematical expectation; SFRP and TRP are steady-flow and transient random processes respectively; and $\mathrm{CF}$ is correlation function.

It is common knowledge that linear voltages are polyharmonic sequence being a full amount of repetitive signals which frequencies are divisible by $\omega=314 \mathrm{rad} / \mathrm{s} \omega=314 \mathrm{paA} / \mathrm{c}$. Taking into consideration the fact that the harmonic signal components, which frequencies are higher than 
harmonic six, effect AM operation nonessentially ${ }^{7}$; hence, it is proposed not to involve them for further analysis.

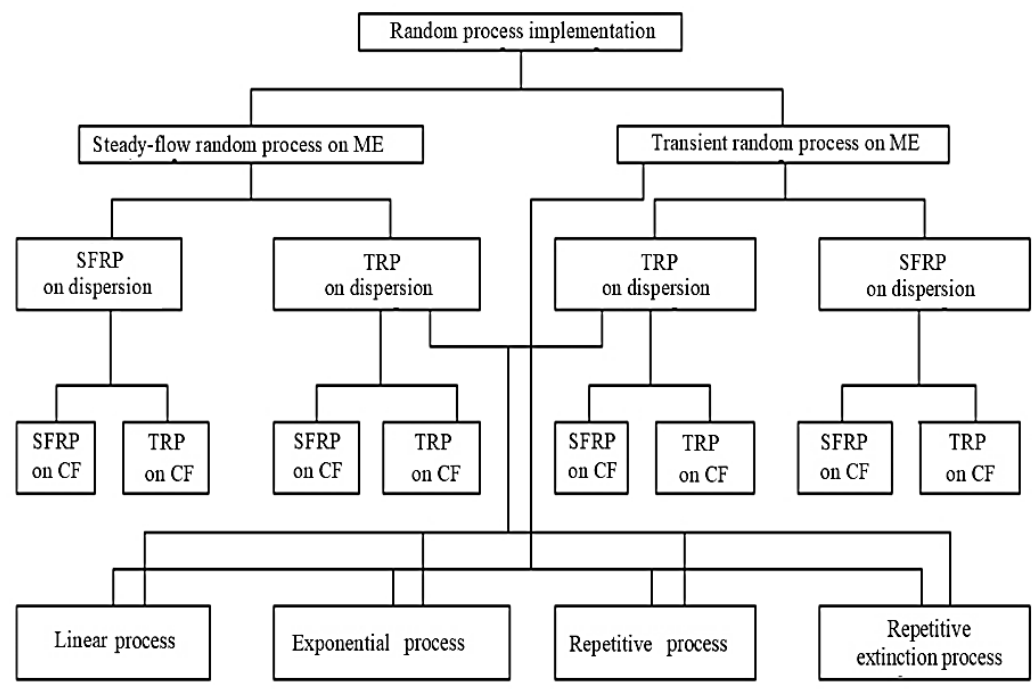

Fig. 2. Classification of random processes

The linear voltages, generated in the process of the passive industrial implementation experiment, are transient ones. Thus, beforehand each implementation was visually divided into steady-flow sections (i.e. certain temporal fragments with invariant signal format). Each of the fragments was enumerated in the order of time increasing.

The enumerated random sequences were tested on the steady state of the average according to inversion criterion. Taking into consideration the fact that the latter is parametric, its application does not involve any preliminary determination of distribution laws for random values and their parameters. To accept zero hypothesis that there are no average drift, it is quite sufficient to use following inequality:

${ }^{7}$ Kuznetsov Vitaliy, Tryputen Nikolay, Kuznetsova Yevheniia Evaluating the Effect of Electric Power Quality upon the Efficiency of Electric Power Consumption, 2019 IEEE 2nd Ukraine Conference on Electrical and Computer Engineering (UKRCON), Lviv, Ukraine, 2019, pp. 556-561, doi: 10.1109/UKRCON.2019.8879841. 


$$
\left[\xi / \sigma_{\xi}^{2}\right]<\Xi\left(\frac{1+v_{0}}{2}\right)
$$

where $\xi$ is test statistic; $\sigma_{\xi}^{2}$ is statistic dispersion $\xi ; \Xi \Xi$ is critical value of a zero hypothesis criterion; $v_{0}$ is probability of the assumed zero hypothesis, if it is valid (confidence probability).

$\xi \xi$ and $\sigma_{\xi}^{2}$ values are calculated on the formulas:

$$
\begin{aligned}
\xi & =1-\frac{4 \cdot \Omega_{I}}{\Omega_{C} \cdot\left(\Omega_{C}-1\right)}, \\
\sigma_{\xi}^{2} & =\frac{2 \cdot\left(2 \cdot \Omega_{C}-5\right)}{9 \cdot \Omega_{C} \cdot\left(\Omega_{C}-1\right)},
\end{aligned}
$$

where $\Omega_{I}$ is the total number of inversions; and $\Omega_{\mathrm{c}} \Omega_{\mathrm{c}}$ is the number of averages within the sequence under study.

The tests results have specified steady-state sections of random sequences resulting from the industrial experiment. Amplitudes of harmonic components of linear voltages within the steady-state stations as well as their phases were considered as invariant ones.

Generally, analytical expressions of distribution laws to describe the linear voltages, being studied, are selected basing upon the problem root. Specifically, simultaneous operating electrical facilities effect parameters of harmonic components of linear voltages.

Moreover, effect of each of them is random one. If there are more than six simultaneous operating electrical facilities, it is quite proper thing to suggest a hypothesis concerning normality of distribution of amplitudes and phases of harmonic components in the context of each steady-state section of random implementations basing upon central limit theorem of probability theory. The hypothesis has been tested according to Shapiro-Wilk normality test ${ }^{8}$. Parameters of distribution laws are summarized in Tables 1-3.

It should be also meant that changes in amplitudes of harmonic components of linear voltages as well as in their phases take place at random time intervals. Analysis of numerical characteristics of the time intervals as well as further tests of several hypotheses concerning distribution laws (normal, exponential, and uniform one) according to Pearson criterion have demonstrated that their description should accept

8 Кобзарь А.И. Прикладная математическая статистика. Москва : Физматлит, 2006. 238 с. 
a hypothesis on exponential distribution law with $\Delta T_{c p}=18$ min average value and $\lambda=1 / \Delta T_{c p}=1 / 18 м и н^{-1} \lambda=1 / \Delta \mathrm{T}_{\mathrm{cp}}=1 / 18 \mathrm{Mин}^{-1}$ intensity:

$$
f(\Delta T)=\frac{1}{18} e^{-\frac{1}{18} \cdot \Delta T}
$$

Table 1

Numerical characteristics of harmonics of linear voltage $U_{A B}$

\begin{tabular}{|c|c|c|c|c|c|}
\hline \multirow{2}{*}{ Harmonic } & \multirow{2}{*}{$\begin{array}{c}\text { Fequency, } \\
\text { rad/s }\end{array}$} & \multicolumn{2}{|c|}{ Amplitude, V } & \multicolumn{2}{c|}{ Phase, degrees } \\
\cline { 3 - 6 } & 314 & Average & Dispersion & Average & Dispersion \\
\hline 1 & 629.82 & 19.11 & - & - \\
\hline 2 & 628 & 4.23 & 1.42 & 63 & 112 \\
\hline 3 & 942 & 17.60 & 9.35 & 206 & 68 \\
\hline 4 & 1256 & 1.51 & 0.06 & 92 & 85 \\
\hline 5 & 1570 & 18.54 & 8.29 & 130 & 214 \\
\hline 6 & 1884 & 3.05 & 0.27 & 290 & 152 \\
\hline
\end{tabular}

Table 2

Numerical characteristics of harmonics of linear voltage $U_{B C}$

\begin{tabular}{|c|c|c|c|c|c|}
\hline \multirow{2}{*}{ Harmonic } & \multirow{2}{*}{$\begin{array}{c}\text { Frequency, } \\
\text { rad/s }\end{array}$} & \multicolumn{2}{|c|}{ Amplitude, V } & \multicolumn{2}{c|}{ Phase, degrees } \\
\cline { 3 - 6 } & Average & Dispersion & Average & Dispersion \\
\hline 1 & 314 & 532.09 & 17.36 & - & - \\
\hline 2 & 628 & 3.98 & 1.56 & 78 & 102 \\
\hline 3 & 942 & 19.13 & 8.19 & 235 & 49 \\
\hline 4 & 1256 & 1.55 & 0.06 & 111 & 106 \\
\hline 5 & 1570 & 16.77 & 6.44 & 114 & 210 \\
\hline 6 & 1884 & 4.15 & 1.11 & 325 & 138 \\
\hline
\end{tabular}

Table 3

Numerical characteristics of harmonics of linear voltage $U_{C A}$

\begin{tabular}{|c|c|c|c|c|c|}
\hline \multirow{2}{*}{ Harmonic } & \multirow{2}{*}{$\begin{array}{c}\text { Frequency, } \\
\text { rad/s }\end{array}$} & \multicolumn{2}{|c|}{ Amplitude, V } & \multicolumn{2}{c|}{ Phase, degrees } \\
\cline { 3 - 6 } & 314 & Average & Dispersion & Average & Dispersion \\
\hline 1 & 330.41 & 17.28 & - & - \\
\hline 2 & 628 & 3.71 & 1.25 & 94 & 96 \\
\hline 3 & 942 & 18.27 & 7.14 & 182 & 78 \\
\hline 4 & 1256 & 1.50 & 0.06 & 83 & 56 \\
\hline 5 & 1570 & 16.01 & 7.66 & 165 & 183 \\
\hline 6 & 1884 & 3.82 & 0.53 & 310 & 240 \\
\hline
\end{tabular}

To identify correlation ratio between amplitudes (phases) of harmonics of linear voltages of the same frequency, both autocorrelation 
functions and cross-correlation ones were calculated. In this context, steady-state section number was taken as actual parameters. That made it possible to assess statistic dependence of amplitudes (phases) of harmonic components in the process of electric workshop equipment switching on/switching off taking place at random time moments.

Approximation of the calculated curves should be based upon general theoretical factors concerning initiation of random processes. If they are unknown, attention should be paid to common nature of correlation function, and compare them with representative curves. In such cases, certain support points are used where experimental values as well as values, calculated on approximating value, coincide. Points, within which ordinates of experimental curve are equal to zero, are applied as support ones.

To approximate autocorrelation function of harmonic components, a representative curve, being described with the help of following analytical expression, has been selected:

$$
R(i)=\sigma^{2} e^{-j \cdot i} \cos (\theta \cdot i),
$$

where $j$ and $\theta$ tare the curve coefficients, and $\sigma$ is a mean-square deviation of a random function.

Similar expression, where graph shift along abscise axis is $\mathrm{m}$ pitches, may be used to approximate cross-correlation function:

$$
R(i)=\sigma^{2} e^{-j \cdot i} \cos (\theta \cdot i-m) .
$$

$j, \mathbf{j} \theta$, and $m$ coefficients of the considered functions for amplitudes and phases of linear voltages of the mentioned workshop are in the corresponding Tables 4-11.

Table 4

Coefficients of analytical curves of autocorrelation functions of amplitudes of harmonics of linear voltages

\begin{tabular}{|c|c|c|c|c|c|c|}
\hline \multirow{3}{*}{ Harmonic } & \multicolumn{6}{|c|}{ Linear voltages } \\
\cline { 2 - 7 } & \multicolumn{2}{|c|}{$U_{A B}$} & \multicolumn{2}{c|}{$U_{B C}$} & \multicolumn{2}{c|}{$U_{C A}$} \\
\cline { 2 - 7 } & $J$ & $\theta$ & $J$ & $\theta$ & $J$ & $\theta$ \\
\hline 1 & 0.85 & 4.1 & 0.61 & 2.9 & 0.5 & 0.47 \\
\hline 2 & 1.4 & - & 0.52 & - & 0.52 & - \\
\hline 3 & 0.73 & - & 0.87 & 1.3 & 1.0 & - \\
\hline 4 & 0.51 & 3.12 & 0.61 & 2.1 & 0.5 & 0.47 \\
\hline 5 & 1.73 & - & 1.81 & - & 1.79 & - \\
\hline 6 & 0.49 & 1.57 & 1.11 & 0.50 & 0.5 & 0.47 \\
\hline
\end{tabular}

Table 5 
Coefficients of analytical curves of autocorrelation functions of phases of harmonics of linear voltages

\begin{tabular}{|c|c|c|c|c|c|c|}
\hline \multirow{3}{*}{ Harmonic } & \multicolumn{6}{|c|}{ Linear voltages } \\
\cline { 2 - 7 } & \multicolumn{2}{|c|}{$U_{A B}$} & \multicolumn{2}{c|}{$U_{B C}$} & \multicolumn{2}{c|}{$U_{C A}$} \\
\cline { 2 - 7 } & $J$ & $\theta$ & $J$ & $\theta$ & $J$ & $\theta$ \\
\hline 1 & 2 & 3 & 4 & 5 & 6 & 7 \\
\hline 1 & 2 & 3 & 4 & 5 & 6 & 7 \\
\hline 1 & - & - & - & - & - & - \\
\hline 2 & 0.87 & 5.2 & 0.72 & 3.80 & 0.79 & 4.30 \\
\hline 3 & 0.52 & - & 0.60 & - & 0.57 & 1.20 \\
\hline 4 & 0.61 & - & 0.56 & 0.50 & 0.69 & - \\
\hline 5 & 1.20 & 1.10 & 0.97 & 1.80 & 0.83 & 1.5 \\
\hline 6 & 0.67 & 0.8 & 0.52 & 0.95 & 0.49 & 0.88 \\
\hline
\end{tabular}

Table 6

Coefficients of analytical curves of cross-correlation functions of amplitudes of harmonics of linear voltages

\begin{tabular}{|c|c|c|c|c|c|c|}
\hline \multirow{3}{*}{ Harmonic } & \multicolumn{6}{|c|}{ Linear voltages } \\
\cline { 2 - 7 } & \multicolumn{3}{|c|}{$U_{A B / B C}$} & \multicolumn{3}{|c|}{$U_{A B / C A}$} \\
\cline { 2 - 7 } & $\boldsymbol{J}$ & $\theta$ & $m$ & & & \\
\hline 1 & 0.51 & 3.12 & 3 & 0.61 & 2.9 & 3 \\
\hline 2 & 1.73 & - & 2 & 0.52 & - & 3 \\
\hline 3 & 0.49 & 1.57 & 2 & 0.87 & 1.3 & 1 \\
\hline 4 & 0.52 & - & 1 & 0.5 & 0.47 & 2 \\
\hline 5 & 1.0 & - & 2 & 0.52 & - & 2 \\
\hline 6 & 0.5 & 0.47 & 1 & 0.87 & 1.3 & 2 \\
\hline
\end{tabular}

Table 7

Coefficients of analytical curves of cross-correlation functions of amplitudes of harmonics of linear voltages

\begin{tabular}{|c|c|c|c|c|c|c|}
\hline \multirow{3}{*}{ Harmonic } & \multicolumn{6}{|c|}{ Linear voltages } \\
\cline { 2 - 7 } & \multicolumn{3}{|c|}{$U_{B C / A B}$} & \multicolumn{3}{c|}{$U_{B C / C A}$} \\
\cline { 2 - 7 } & $\boldsymbol{j}$ & $\theta$ & $\boldsymbol{m}$ & $\boldsymbol{j}$ & $\theta$ & $\boldsymbol{m}$ \\
\hline 1 & 0.87 & 1.3 & 3 & 0.52 & - & 2 \\
\hline 2 & 0.61 & 2.1 & 3 & 1.0 & - & 2 \\
\hline 3 & 1.81 & - & 2 & 0.85 & 4.1 & 3 \\
\hline 4 & 0.87 & 1.3 & 1 & 1.4 & - & 1 \\
\hline 5 & 0.61 & 2.1 & 2 & 0.87 & 1.3 & 1 \\
\hline 6 & 0.5 & 0.47 & 3 & 0.61 & 2.1 & 2 \\
\hline
\end{tabular}

Table 8 
Coefficients of analytical curves of cross-correlation functions of amplitudes of harmonics of linear voltages

\begin{tabular}{|c|c|c|c|c|c|c|}
\hline \multirow{3}{*}{ Harmonic } & \multicolumn{6}{|c|}{ Linear voltages } \\
\cline { 2 - 7 } & \multicolumn{3}{|c|}{$U_{C A / A B}$} & \multicolumn{3}{c|}{$U_{C A / B C}$} \\
\cline { 2 - 7 } & $\boldsymbol{j}$ & $\theta$ & $\boldsymbol{m}$ & $\boldsymbol{j}$ & $\theta$ & $\boldsymbol{m}$ \\
\hline 1 & 0.52 & - & 2 & 1.4 & - & 2 \\
\hline 2 & 0.61 & 2.1 & 2 & 0.73 & - & 3 \\
\hline 3 & 1.81 & - & 3 & 1.79 & - & 3 \\
\hline 4 & 1.0 & - & 1 & 1.73 & - & 2 \\
\hline 5 & 0.87 & 1.3 & 3 & 0.61 & 2.1 & 2 \\
\hline 6 & 0.51 & 3.12 & 3 & 0.49 & 1.57 & 3 \\
\hline
\end{tabular}

Table 9

Coefficients of analytical curves of cross-correlation functions of phases of harmonics of linear voltages

\begin{tabular}{|c|c|c|c|c|c|c|}
\hline \multirow{3}{*}{ Harmonic } & \multicolumn{6}{|c|}{ Linear voltages } \\
\cline { 2 - 7 } & \multicolumn{3}{|c|}{$U_{A B / B C}$} & \multicolumn{3}{c|}{$U_{A B / C A}$} \\
\cline { 2 - 7 } & $\boldsymbol{j}$ & $\theta$ & $\boldsymbol{m}$ & $\boldsymbol{j}$ & $\theta$ & $\boldsymbol{m}$ \\
\hline 1 & 0.56 & 0.50 & 1 & 0.50 & 0.69 & 2 \\
\hline 2 & 0.97 & 1.80 & 3 & 0.52 & - & 2 \\
\hline 3 & 0.87 & 5.2 & 3 & 0.61 & - & 2 \\
\hline 4 & 0.83 & 1.5 & 2 & 0.60 & - & 1 \\
\hline 5 & 0.49 & 0.88 & 1 & 0.56 & 0.50 & 1 \\
\hline 6 & 1.20 & 1.10 & 1 & 0.67 & 0.8 & 1 \\
\hline
\end{tabular}

Table 10

Coefficients of analytical curves of cross-correlation functions of phases of harmonics of linear voltages

\begin{tabular}{|c|c|c|c|c|c|c|}
\hline \multirow{3}{*}{ Harmonic } & \multicolumn{6}{|c|}{ Linear voltages } \\
\cline { 2 - 7 } & \multicolumn{3}{|c|}{$U_{B C / A B}$} & \multicolumn{3}{c|}{$U_{B C / C A}$} \\
\cline { 2 - 7 } & $\boldsymbol{j}$ & $\theta$ & $\boldsymbol{m}$ & $\boldsymbol{j}$ & $\theta$ & $\boldsymbol{m}$ \\
\hline 1 & 0.69 & - & 2 & 0.60 & - & 2 \\
\hline 2 & 0.83 & 1.5 & 2 & 0.79 & 4.30 & 2 \\
\hline 3 & 0.49 & 0.88 & 3 & 0.57 & 1.20 & 1 \\
\hline 4 & 0.56 & 0.50 & 1 & 0.87 & 5.2 & 1 \\
\hline 5 & 0,97 & 1.80 & 2 & 0.52 & - & 2 \\
\hline 6 & 0.52 & 0.95 & 2 & 0.52 & 0.95 & 3 \\
\hline
\end{tabular}

Table 11 
Coefficients of analytical curves of cross-correlation functions of phases of harmonics of linear voltages

\begin{tabular}{|c|c|c|c|c|c|c|}
\hline \multirow{3}{*}{ Harmonic } & \multicolumn{6}{|c|}{ Linear voltages } \\
\cline { 2 - 7 } & \multicolumn{3}{|c|}{$U_{C A / A B}$} & \multicolumn{3}{c|}{$U_{C A / B C}$} \\
\cline { 2 - 7 } & $\boldsymbol{j}$ & $\theta$ & $\boldsymbol{m}$ & $\boldsymbol{j}$ & $\theta$ & $\boldsymbol{m}$ \\
\hline 1 & 1.20 & 1.10 & 2 & 0.87 & 5.2 & 3 \\
\hline 2 & 0.67 & 0.8 & 3 & 0.52 & - & 3 \\
\hline 3 & 0.60 & - & 1 & 0.97 & 1.80 & 2 \\
\hline 4 & 0.56 & 0.50 & 2 & 0.52 & 0.95 & 1 \\
\hline 5 & 0.79 & 4.30 & 2 & 0.61 & - & 3 \\
\hline 6 & 0,57 & 1.20 & 3 & 0.56 & 0.50 & 2 \\
\hline
\end{tabular}

\section{Digital implementation of statistical models of the electrical system of the production structure of an industrial enterprise}

While implementing voltage generators within power grid, it is required to have signals with standard distribution laws to simulate amplitudes and phases of their harmonic components as well as exponential law for time intervals between electric equipment switching on/switching off. Currently, almost each application program package (for instance, MatLAB), intended to solve such problems, has built-in functions helping model random values including those with standard law. As for the exponential law, it is more expedient to use a method of inverse functions.

Idea of the method is as follows ${ }^{9}$. Mathematical ratio is known; it connects random numbers $y_{i}$ with the prescribed distribution law $f(y)$, and $x_{i}$ number distributed uniformly within $[0 ; 1]$ interval $^{10}$ :

$$
x=\int_{\infty}^{y} f(y) d y .
$$

If there is integral in a right side, then:

$$
x=F(y) .
$$

${ }^{9}$ Hastie, T., Tibshirani, R., Friedman, J.: The Elements of Statistical Learning: Data Mining, Inference, and Prediction, Second Edition. 745 p., Springer Science+Business Media, Ney York, USA (2017).

10 Гмурман В.Е. Руководство к решению задач по теории вероятности и математической статистике: Учеб. пособие для студентов вузов. Москва : Высш. шк., 2004. 404 с. 
Further, inverse function $F^{-1}(x)$ is being determined to identify dependence according to which the numbers are generated:

$$
y=F^{-1}(x)
$$

Numbers, distributed uniformly within $[0 ; 1]$ interval, are connected with exponential law with the help of following mathematical expression:

$$
x=\int_{0}^{y} \frac{1}{18} e^{-\frac{1}{18} \cdot \Delta T} d y .
$$

Determine integral in a right side:

$$
x=\int_{0}^{y} \frac{1}{18} e^{-\frac{1}{18} \cdot \Delta T} d y=-\left.e^{-\frac{1}{18} \Delta T}\right|_{0} ^{y}=-e^{-\frac{1}{18} \Delta T}+1
$$

as well as inverse function:

$$
\Delta T=-18 \cdot \ln (1-x) .
$$

Uncorrelated random values are transformed into a sequence with the prescribed autocorrelation function and cross-correlation one using moving average method; it is based upon the use of the dependence ${ }^{11}$ :

$$
X(l)=\sum_{j=-\infty}^{\infty} S_{j} I(i-j),
$$

where $\mathrm{X}(\mathrm{l})$ is a running $l$ value of a centered random variable; $S_{j}$ are real numbers or complex numbers; and I is a unit random sequence.

In this context, autocorrelation function $R(i)$ can be determined as follows:

$$
R(i)=\sum_{j=-\infty}^{\infty} S_{j+i} S_{j} .
$$

If $\mathrm{R}(\mathrm{i})$ is attenuating, (18 and 19) ratios are:

$$
\begin{gathered}
X(l)=\sum_{j=0}^{\eta_{3}} S_{j} \cdot I(l-j), \\
R(i)=\left\{\begin{array}{c}
\sum_{j=0}^{\eta_{3}-|i|} S_{j+|i|} \cdot S_{j}, \text { when }|i| \leq \eta_{3}, \\
0, \text { when }|i|>\eta_{3}
\end{array}\right.
\end{gathered}
$$

where $\eta_{3}$ is attenuating interval of cross-correlation function of a random process.

In practice, $\eta_{3}$ value is selected in such a way to fulfill the inequality:

11 A. Papoulis and S.U. Pillai, Probability, Random Variables and Stochastic Processes. New York : McGraw-Hill, 2001. 


$$
R\left(\eta_{3}\right) \geq 0.05 R(0) \text {. }
$$

Determination of $S_{j} S_{j}$ coefficients is to solve (21) when $i$ is varying from 0 to $\eta_{3}$, i.e. to solve a set of the equations:

$$
\left\{\begin{array}{c}
R(0)=S_{0}^{2}+S_{1}^{2}+\cdots+S_{\eta_{3}}^{2} \\
R(1)=S_{1} S_{0}+S_{2} S_{1}+\cdots+S_{\eta_{3}} S_{\eta_{3}-1} \\
\cdots \\
R\left(\eta_{3}-1\right)=S_{\eta_{3}-1} S_{0}+S_{\eta_{3}} S_{1} \\
R\left(\eta_{3}\right)=S_{\eta_{3}} S_{0}
\end{array} .\right.
$$

The last equation has been implemented in an application program package MathCAD.

$R(i)$ values for workshop grid of Dneprospetsstal PJSC have been determined according to analytical expressions of corresponding autocorrelation functions; in this context, Tables 12-22 explain values of the related coefficients to simulate amplitudes of harmonic components, and their phases.

Table 12

Coefficients to simulate amplitudes of linear voltages of harmonic one

\begin{tabular}{|c|c|c|c|c|c|c|c|c|c|}
\hline & $U_{A B}$ & $U_{B C}$ & $U_{C A}$ & $U_{A B / B C}$ & $U_{A B / C A}$ & $U_{B C / A B}$ & $U_{B C / C A}$ & $U_{C A / A B}$ & $U_{C A / B C}$ \\
\hline$S_{o}$ & 0.95 & 3.537 & 0.634 & 0.93 & -0.197 & 0.362 & 0.195 & 0.387 & -0.051 \\
\hline$S_{1}$ & 1.91 & -1.909 & 1.177 & -0.53 & -0.713 & 0.077 & 0.311 & 0.637 & -0.006 \\
\hline$S_{2}$ & 1.83 & 0.969 & 1.939 & 2.84 & 2.571 & 2.458 & -0.01 & -0.002 & 0.049 \\
\hline$S_{3}$ & -2.99 & -0.458 & 2.447 & 2.72 & 1.015 & 0.98 & -0.312 & -0.637 & 0.166 \\
\hline$S_{4}$ & 1.52 & 0.43 & 1.804 & 1.03 & - & - & 0.194 & 0.386 & 0.361 \\
\hline$S_{5}$ & - & - & -1.577 & - & - & - & 0.195 & 0.387 & -0.051 \\
\hline
\end{tabular}

Table 13

Coefficients to simulate amplitudes of linear voltages of harmonic two

\begin{tabular}{|c|c|c|c|c|c|c|c|c|c|}
\hline & $U_{A B}$ & $U_{B C}$ & $U_{C A}$ & $U_{A B / B C}$ & $U_{A B / C A}$ & $U_{B C / A B}$ & $U_{B C / C A}$ & $U_{C A / A B}$ & $U_{C A / B C}$ \\
\hline$S_{o}$ & 0.07 & 0.389 & 0.694 & -0.051 & -0.197 & 0.362 & 0.07 & -0.022 & 0.93 \\
\hline$S_{1}$ & 0.02 & -0.189 & -0.166 & -0.006 & -0.713 & 0.077 & 0.03 & -0.092 & -0.53 \\
\hline$S_{2}$ & 1.16 & 0.446 & 0.151 & 0.049 & 2.571 & 2.458 & 0.06 & 0.074 & 2.84 \\
\hline$S_{3}$ & 028 & 0.816 & 0.218 & 0.166 & 1.015 & 0.98 & -0.15 & 0.079 & 2.72 \\
\hline$S_{4}$ & - & 0.647 & 0.546 & 0.361 & - & - & 0.15 & 0.116 & 1.03 \\
\hline$S_{5}$ & - & 0.298 & 1.339 & 0.606 & - & - & -0.08 & 0.18 & - \\
\hline
\end{tabular}


Table 14

Coefficients to simulate phases of linear voltages of harmonic two

\begin{tabular}{|c|c|c|c|c|c|c|c|c|c|}
\hline & $U_{A B}$ & $U_{B C}$ & $U_{C A}$ & $U_{A B / B C}$ & $U_{A B / C A}$ & $U_{B C / A B}$ & $U_{B C / C A}$ & $U_{C A / A B}$ & $U_{C A / B C}$ \\
\hline$S_{o}$ & -0.79 & 2.21 & 1.88 & -0.79 & 2.21 & 1.88 & 7.72 & -2.69 & 6.47 \\
\hline$S_{1}$ & -0.89 & -5.51 & -5.61 & -0.89 & -5.51 & -5.61 & 4.21 & 6.56 & 3.25 \\
\hline$S_{2}$ & 2.27 & 7.90 & 6.37 & 2.27 & 7.90 & 6.37 & 2.92 & 6.22 & 1.63 \\
\hline$S_{3}$ & 10.26 & 2.10 & 4.52 & 10.26 & 2.10 & 4.52 & 1.24 & 3.74 & 0.83 \\
\hline$S_{4}$ & - & - & - & - & - & - & 0.96 & 1.75 & 0.54 \\
\hline$S_{5}$ & - & - & & - & - & & - & -0.5 & - \\
\hline
\end{tabular}

Table 15

Coefficients to simulate amplitudes of linear voltages of harmonic three

\begin{tabular}{|c|c|c|c|c|c|c|c|c|c|}
\hline & $U_{A B}$ & $U_{B C}$ & $U_{C A}$ & $U_{A B / B C}$ & $U_{A B / C A}$ & $U_{B C / A B}$ & $U_{B C / C A}$ & $U_{C A / A B}$ & $U_{C A / B C}$ \\
\hline$S_{o}$ & 0.93 & -0.197 & 0.362 & 0.362 & 0.195 & 0.07 & -0.022 & 0.07 & -0.197 \\
\hline$S_{1}$ & -0.53 & -0.713 & 0.077 & 0.077 & 0.311 & 0.03 & -0.092 & 0.03 & -0.713 \\
\hline$S_{2}$ & 2.84 & 2.571 & 2.458 & 2.458 & -0.01 & 0.06 & 0.074 & 0.06 & 2.571 \\
\hline$S_{3}$ & 2.72 & 1.015 & 0.98 & 0.98 & -0.312 & -0.15 & 0.079 & -0.15 & 1.015 \\
\hline$S_{4}$ & 1.03 & - & - & - & 0.194 & 0.15 & 0.116 & 0.15 & - \\
\hline$S_{5}$ & - & - & - & - & 0.195 & -0.08 & 0.18 & -0.08 & - \\
\hline
\end{tabular}

Table 16

\section{Coefficients to simulate phases of linear voltages of harmonic three}

\begin{tabular}{|c|c|c|c|c|c|c|c|c|c|}
\hline & $U_{A B}$ & $U_{B C}$ & $U_{C A}$ & $U_{A B / B C}$ & $U_{A B / C A}$ & $U_{B C / A B}$ & $U_{B C / C A}$ & $U_{C A / A B}$ & $U_{C A / B C}$ \\
\hline$S_{o}$ & 6.63 & 3.57 & 1.45 & 2.01 & 3.61 & 3.61 & 14.29 & 7.72 & -2.69 \\
\hline$S_{1}$ & 3.92 & 5.63 & -1.76 & 5.14 & 7.25 & 7.25 & -1.46 & 4.21 & 6.56 \\
\hline$S_{2}$ & 2.34 & 0.86 & -4.39 & 7.07 & 9.09 & 9.09 & -1.90 & 2.92 & 6.22 \\
\hline$S_{3}$ & 1.40 & 1.84 & 5.27 & 3.45 & 4.03 & 4.03 & - & 1.24 & 3.74 \\
\hline$S_{4}$ & 0.83 & 0.17 & 4.12 & -6.76 & -8.69 & -8.69 & - & 0.96 & 1.75 \\
\hline$S_{5}$ & 0.77 & 0.67 & 2.98 & - & - & - & - & - & -0.5 \\
\hline
\end{tabular}

Table 17

Coefficients to simulate amplitudes

of linear voltages of harmonic four

\begin{tabular}{|c|c|c|c|c|c|c|c|c|c|}
\hline & $U_{A B}$ & $U_{B C}$ & $U_{C A}$ & $U_{A B / B C}$ & $U_{A B / C A}$ & $U_{B C / A B}$ & $U_{B C / C A}$ & $U_{C A / A B}$ & $U_{C A / B C}$ \\
\hline$S_{o}$ & 0.195 & 0.07 & -0.022 & 0.07 & -0.022 & 0.694 & -0.051 & 0.387 & -0.051 \\
\hline$S_{1}$ & 0.311 & 0.03 & -0.092 & 0.03 & -0.092 & -0.166 & -0.006 & 0.637 & -0.006 \\
\hline$S_{2}$ & -0.01 & 0.06 & 0.074 & 0.06 & 0.074 & 0.151 & 0.049 & -0.002 & 0.049 \\
\hline$S_{3}$ & -0.312 & -0.15 & 0.079 & -0.15 & 0.079 & 0.218 & 0.166 & -0.637 & 0.166 \\
\hline$S_{4}$ & 0.194 & 0.15 & 0.116 & 0.15 & 0.116 & 0.546 & 0.361 & 0.386 & 0.361 \\
\hline$S_{5}$ & 0.195 & -0.08 & 0.18 & -0.08 & 0.18 & 1.339 & 0.606 & 0.387 & -0.051 \\
\hline
\end{tabular}


Table 18

Coefficients to simulate phases of linear voltages of harmonic four

\begin{tabular}{|c|c|c|c|c|c|c|c|c|c|}
\hline & $U_{A B}$ & $U_{B C}$ & $U_{C A}$ & $U_{A B / B C}$ & $U_{A B / C A}$ & $U_{B C / A B}$ & $U_{B C / C A}$ & $U_{C A / A B}$ & $U_{C A / B C}$ \\
\hline$S_{o}$ & 7.72 & -2.69 & 6.47 & 13.27 & 3.57 & 14.29 & 7.72 & 14.29 & 6.30 \\
\hline$S_{1}$ & 4.21 & 6.56 & 3.25 & 0.53 & 5.63 & -1.46 & 4.21 & -1.46 & 10.41 \\
\hline$S_{2}$ & 2.92 & 6.22 & 1.63 & -2.60 & 0.86 & -1.90 & 2.92 & -1.90 & -1.03 \\
\hline$S_{3}$ & 1.24 & 3.74 & 0.83 & - & 1.84 & - & 1.24 & - & 0.35 \\
\hline$S_{4}$ & 0.96 & 1.75 & 0.54 & - & 0.17 & - & 0.96 & - & -1.66 \\
\hline$S_{5}$ & - & - & - & - & 0.67 & - & - & - & - \\
\hline
\end{tabular}

Table 19

Coefficients to simulate amplitudes of linear voltages of harmonic five

\begin{tabular}{|c|c|c|c|c|c|c|c|c|c|}
\hline & $U_{A B}$ & $U_{B C}$ & $U_{C A}$ & $U_{A B / B C}$ & $U_{A B / C A}$ & $U_{B C / A B}$ & $U_{B C / C A}$ & $U_{C A / A B}$ & $U_{C A / B C}$ \\
\hline$S_{o}$ & 2.83 & 2.50 & 2.728 & 2.456 & 2.673 & 13.234 & 0.195 & 0.387 & -0.051 \\
\hline$S_{1}$ & 0.52 & 0.42 & 0.469 & -0.051 & -0.197 & 0.362 & 0.311 & 0.637 & -0.006 \\
\hline$S_{2}$ & - & - & - & -0.006 & -0.713 & 0.077 & -0.01 & -0.002 & 0.049 \\
\hline$S_{3}$ & 2 & 3 & 4 & 5 & 6 & 7 & 8 & 9 & 10 \\
\hline$S_{4}$ & - & - & - & 0.049 & 2.571 & 2.458 & -0.312 & -0.637 & 0.166 \\
\hline$S_{5}$ & - & - & - & 0.166 & 1.015 & 0.98 & 0.194 & 0.386 & 0.361 \\
\hline
\end{tabular}

Table 20

Coefficients to simulate phases of linear voltages of harmonic five

\begin{tabular}{|c|c|c|c|c|c|c|c|c|c|}
\hline & $U_{A B}$ & $U_{B C}$ & $U_{C A}$ & $U_{A B / B C}$ & $U_{A B / C A}$ & $U_{B C / A B}$ & $U_{B C / C A}$ & $U_{C A / A B}$ & $U_{C A / B C}$ \\
\hline$S_{o}$ & -0.79 & 14.29 & 13.27 & 1.88 & -0.79 & 2.21 & 1.88 & 3.61 & 6.47 \\
\hline$S_{1}$ & 2.14 & -1.46 & 0.53 & -5.61 & -0.89 & -5.51 & -5.61 & 7.25 & 3.25 \\
\hline$S_{2}$ & 14.45 & -1.90 & -2.60 & 6.37 & 2.27 & 7.90 & 6.37 & 9.09 & 1.63 \\
\hline$S_{3}$ & - & - & - & 4.52 & 10.26 & 2.10 & 4.52 & 4.03 & 0.83 \\
\hline$S_{4}$ & - & - & - & - & - & - & - & -8.69 & 0.54 \\
\hline$S_{5}$ & - & - & - & & - & 2.21 & 1.88 & - & - \\
\hline
\end{tabular}

Table 21

Coefficients to simulate amplitudes of linear voltages of harmonic six

\begin{tabular}{|c|c|c|c|c|c|c|c|c|c|}
\hline & $U_{A B}$ & $U_{B C}$ & $U_{C A}$ & $U_{A B / B C}$ & $U_{A B / C A}$ & $U_{B C / A B}$ & $U_{B C / C A}$ & $U_{C A / A B}$ & $U_{C A / B C}$ \\
\hline$S_{o}$ & 0.195 & 0.387 & -0.051 & 0.195 & 0.07 & -0.022 & 0.93 & 0.95 & 3.537 \\
\hline$S_{1}$ & 0.311 & 0.637 & -0.006 & 0.311 & 0.03 & -0.092 & -0.53 & 1.91 & -1.909 \\
\hline$S_{2}$ & -0.01 & -0.002 & 0.049 & -0.01 & 0.06 & 0.074 & 2.84 & 1.83 & 0.969 \\
\hline$S_{3}$ & -0.312 & -0.637 & 0.166 & -0.312 & -0.15 & 0.079 & 2.72 & -2.99 & -0.458 \\
\hline$S_{4}$ & 0.194 & 0.386 & 0.361 & 0.194 & 0.15 & 0.116 & 1.03 & 1.52 & 0.243 \\
\hline$S_{5}$ & 0.001 & 0.001 & 0.606 & 0.195 & -0.08 & 0.18 & - & - & - \\
\hline
\end{tabular}


Table 22

Coefficients to simulate phases of linear voltages of harmonic six

\begin{tabular}{|c|c|c|c|c|c|c|c|c|c|}
\hline & $U_{A B}$ & $U_{B C}$ & $U_{C A}$ & $U_{A B / B C}$ & $U_{A B / C A}$ & $U_{B C / A B}$ & $U_{B C / C A}$ & $U_{C A / A B}$ & $U_{C A / B C}$ \\
\hline$S_{o}$ & 6.30 & 2.01 & 3.61 & 2.21 & 1.88 & 2.21 & -0.022 & 0.07 & -2.69 \\
\hline$S_{1}$ & 10.41 & 5.14 & 7.25 & -5.51 & -5.61 & -5.51 & -0.092 & 0.03 & 6.56 \\
\hline$S_{2}$ & -1.03 & 7.07 & 9.09 & 7.0 & 6.37 & 7.90 & 0.074 & 0.06 & 6.22 \\
\hline$S_{3}$ & 0.35 & 3.45 & 4.03 & 2.10 & 4.52 & 2.10 & 0.079 & -0.15 & 3.74 \\
\hline$S_{4}$ & -1.66 & -6.76 & -8.69 & - & - & - & 0.116 & 0.15 & 1.75 \\
\hline$S_{5}$ & - & - & - & - & & 2.21 & 0.18 & -0.08 & -0.5 \\
\hline
\end{tabular}

Fig. 3 demonstrates enlarged algorithm to simulate sequences of linear voltages with the prescribed statistical regularities.

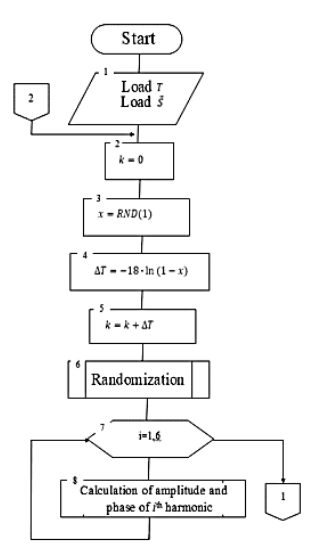

Fig. 3. Algorithm to simulate linear voltages

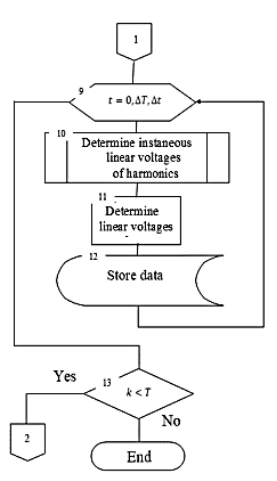

Fig. 4. Randomization algorithm

Unit 1 loads modeling timeT, and array $\vec{S}$ used to transform uncorrelated random sequences, distributed according to a standard law with zero mathematical expectation as well as with the preset dispersion, into the correlated ones. Unit 2 prepares $k$ variable for further accumulation of intervals of steady-state sections; unit 3 generates uncorrelated random sequences. Unit 4 calculates duration of the current steady-state modeling interval of random values. Unit 5 calculates total duration value of the steady-state sections. 
As it has been stated below, decrease in systematic modeling error of linear voltages is possible owing to randomly selected sequence (i.e. randomization) while generating amplitudes and harmonic phases. Unit 6 performs the procedure. Then, parameter values of linear voltage harmonic are calculated (Units 7 and 8). The obtained values help determine instaneous harmonic values (Unit 10) as well as linear voltages properly (Unit 11). Unit 12 storages them.

Consequently, duration of the current total modeling period is checked (Unit 13). If it is less than the prescribed $T$ then the considered procedure, corresponding to the algorithm, recurs. Otherwise, simulation of random sequences of linear voltages terminates.

Fig. 4 explains randomization algorithm, implemented by Unit 6 . Its idea is as follows. As it has been mentioned above, determination of amplitudes, and harmonic phases of linear voltages within steady-state sections may involve one of the calculation techniques: either relying upon the prescribed autocorrelation functions (i.e. moving-average method) or upon cross-correlation functions (i.e. moving-average retarded method), or upon the known electrotechnical ratios between instaneous values of linear voltages (formulas 2; 10; and 11). Table 23 shows all possible combinations of sequences to calculate linear voltages.

Table 23

\section{Determination of a technique to simulate harmonics} of linear voltages

\begin{tabular}{|c|c|c|c|c|}
\hline & Random value d & $\begin{array}{c}\text { Calculation on } \\
\text { autocorrelation } \\
\text { function }\end{array}$ & $\begin{array}{c}\text { Calculation of } \\
\text { cross-correlation } \\
\text { function }\end{array}$ & $\begin{array}{c}\text { Calculation } \\
\text { on formula } \\
\text { (2) }\end{array}$ \\
\hline 1 & $0 \leq d \leq 1 / 6$ & $U_{A B}$ & $U_{B C}$ & $U_{C A}$ \\
\hline 2 & $1 / 6<d \leq 2 / 6$ & $U_{A B}$ & $U_{C A}$ & $U_{B C}$ \\
\hline 3 & $2 / 6<d \leq 3 / 6$ & $U_{B C}$ & $U_{A B}$ & $U_{C A}$ \\
\hline 4 & $3 / 6<d \leq 4 / 6$ & $U_{B C}$ & $U_{C A}$ & $U_{A B}$ \\
\hline 5 & $4 / 6<d \leq 5 / 6$ & $U_{C A}$ & $U_{A B}$ & $U_{B C}$ \\
\hline 6 & $5 / 6<d \leq 1$ & $U_{C A}$ & $U_{B C}$ & $U_{A B}$ \\
\hline
\end{tabular}

Separate regular numeric intervals for each of them within $[0 ; 1]$. Then, while producing sequence of potential values of random variable $d$ (Unit 1) distributed uniformly within $[0 ; 1]$ interval, it is possible to select one of the sequences randomly (Units 2 and 3). It follows from 
probability theory and from mathematical statistics that selection frequencies will be identical, if tests are numerous.

\section{Estimation of means and variances of random sequences of simulated parameters of the electrical system of the production structure of an industrial enterprise}

While synthesizing digital linear voltage generators within workshop power grids, the techniques, providing computer modeling of random sequences with the prescribed statistic characteristics, were applied. Hence, it is necessary for average values and dispersions of the generated samples to differ insignificantly from the obtained hypothetical average values and dispersions (Tables 1-3). If so, then the computational results may help make correct engineering decisions to provide the required conditions for asynchronous motor functioning. If significance value $\alpha$ is prescribed, then to check zero hypothesis $H_{0}: \sigma^{2}=\sigma_{0}^{2}$ on the equality of the unknown general dispersion $\sigma^{2}$ to hypothetic value $\sigma_{0}^{2}$ in the context of competing hypothesis $H_{1}: \sigma^{2} \neq \sigma_{0}^{2}$ it is required to calculate the experimental criterion ${ }^{12}$ :

$$
\chi_{\text {exp erimental }}^{2}=\frac{(\mathrm{n}-1) s^{2}}{\sigma_{0}^{2}},
$$

where $\mathrm{s}^{2}$ is unbiased dispersion estimator.

Further, it is necessary to determine left critical point $\chi_{\text {левуюкр.(1- } \alpha / 2 ; \mathrm{k})}^{2}$, and right one $\chi_{\text {правуюкр. }(\alpha / 2 ; \mathrm{k})}^{2}(\mathrm{k}=\mathrm{n}-1-$ number of

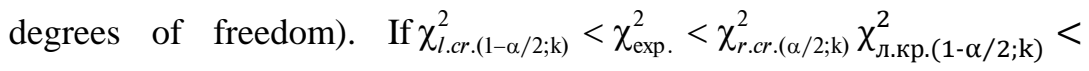
$\chi_{\text {набл }}^{2}<\chi_{\text {п.кр. }(\alpha / 2 ; \mathrm{k})}^{2}$, then zero hypothesis is accepted. In the context of $\mathrm{n}=30$ and $\alpha=0,05$, both left and right critical points are equal to $\chi_{\text {л.кр. }(1-\alpha / 2 ; k)}^{2}=16 \chi_{\text {л.кр. }(1-\alpha / 2 ; \mathrm{k})}^{2}=16$ and $\chi_{n . \kappa p .(\alpha / 2 ; k)}^{2}=42,6 \chi_{\text {п.кр. }(\alpha / 2 ; \mathrm{k})}^{2}=$ 42 ,6respectively. Tables $24-26$ represent results concerning verification of dispersions of random sequences of linear voltage harmonics generated with the help of the developed digital generators.

If significance value $\alpha$ is prescribed, then to check zero hypothesis $H_{0}: a=a_{0}$ on the equality of the general average normal collection $a$

${ }^{12}$ Kendall, M., Gibbons, J.: Rank Correlation Methods. 260 pp. 5th edn., Edward Arnold, London, (1990). 
with the known $\sigma_{0}^{2}$ dispersion to hypothetic value in the context of competing hypothesis $H_{1}: a \neq a_{0}$ it is required to calculate the experimental criterion ${ }^{13}$ :

$$
\mathrm{U}_{\text {exper }}=\frac{\left(\bar{y}-a_{0}\right) \sqrt{n}}{\sigma} .
$$

Then, Laplace function table is applied to find critical point $u_{c r} \mathrm{u}_{\mathrm{\kappa p}}$ of two-sided critical region using the equality:

$$
\Phi\left(\mathrm{u}_{\mathrm{cr}}\right)=(1-\alpha) / 2 .
$$

If $\left|\mathrm{U}_{\text {exp } e r}\right|<u_{c r}$, it is no necessity to reject zero hypothesis.

Determine $\Phi\left(\mathrm{u}_{\mathrm{cr}}\right)=(1-\alpha) / 2=0.475$ for $\alpha=0.05$

$$
\Phi\left(\mathrm{u}_{\mathrm{kp}}\right)=(1-\alpha) / 2=0,475 \Phi\left(\mathrm{u}_{\mathrm{\kappa p}}\right)=(1-\alpha) / 2=0,475 \text {. }
$$

Laplace function table helps identify $u_{c r}=1.96$.

Table 24

Control results of dispersions of linear voltage $U_{\mathrm{AB}}$.

\begin{tabular}{|c|c|c|c|c|c|c|}
\hline \multirow{3}{*}{ Harmonic } & \multicolumn{3}{|c|}{ Amplitude, $\mathrm{V}$} & \multicolumn{3}{c|}{ Phase, degrees } \\
\cline { 2 - 7 } & $\begin{array}{c}\text { Dispersion } \\
\sigma_{0}^{2}\end{array}$ & $\begin{array}{c}\text { Dispersion } \\
s^{2}\end{array}$ & $\chi_{\text {exper }}^{2}$ & $\begin{array}{c}\text { Dispersion } \\
\sigma_{0}^{2}\end{array}$ & $\begin{array}{c}\text { Dispersion } \\
s^{2}\end{array}$ & $\chi_{\text {exper }}^{2}$ \\
\hline 1 & 19.11 & 21.19 & 32.16 & - & - & - \\
\hline 2 & 1.42 & 1.24 & 25.34 & 112 & 70.06 & 18.14 \\
\hline 3 & 9.35 & 6.41 & 19.87 & 68 & 62.16 & 26.51 \\
\hline 4 & 0.06 & 0.04 & 21.19 & 85 & 68.06 & 23.22 \\
\hline 5 & 8.29 & 11.35 & 39.72 & 214 & 276.06 & 37.41 \\
\hline 6 & 0.27 & 0.31 & 33.07 & 152 & 180.51 & 34.44 \\
\hline
\end{tabular}

Table 25

Control results of dispersions of linear voltage $\mathbf{U}_{\mathbf{B C}}$.

\begin{tabular}{|c|c|c|c|c|c|c|}
\hline \multirow{3}{*}{ Harmonic } & \multicolumn{3}{|c|}{ Amplitude, $\mathrm{V}$} & \multicolumn{3}{c|}{ Phase, degrees } \\
\cline { 2 - 7 } & $\begin{array}{c}\text { Dispersion } \\
\sigma_{0}^{2}\end{array}$ & $\begin{array}{c}\text { Dispersion } \\
s^{2}\end{array}$ & $\chi_{\text {exper }}^{2}$ & $\begin{array}{c}\text { Dispersion } \\
\sigma_{0}^{2}\end{array}$ & $\begin{array}{c}\text { Dispersion } \\
s^{2}\end{array}$ & $\chi_{\text {exper }}^{2}$ \\
\hline 1 & 17.36 & 11.87 & 19.83 & - & - & - \\
\hline 2 & 1.56 & 1.02 & 18.92 & 102 & 96.20 & 27.35 \\
\hline 3 & 8.19 & 8.83 & 31.27 & 49 & 40.82 & 24.16 \\
\hline 4 & 0.06 & 0.05 & 22.88 & 106 & 137.99 & 37.75 \\
\hline 5 & 6.44 & 5.59 & 25.17 & 210 & 191.97 & 26.51 \\
\hline
\end{tabular}

${ }^{13}$ Bonett, Douglas G.; Wright, Thomas A. (2000). Sample size requirements for estimating Pearson, Kendall, and Spearman correlations. Psychometrika. 65 (1): 23-28. 


\begin{tabular}{|l|l|l|l|l|l|l|}
\hline 6 & 1.11 & 0.82 & 21.45 & 138 & 144.00 & 30.47 \\
\hline
\end{tabular}

Table 26

Control results of dispersions of linear voltage $\mathrm{U}_{\mathrm{CA}}$

\begin{tabular}{|c|c|c|c|c|c|c|}
\hline \multirow{3}{*}{ Harmonic } & \multicolumn{3}{|c|}{ Amplitude, $\mathrm{V}$} & \multicolumn{3}{c|}{ Phase, degrees } \\
\cline { 2 - 7 } & $\begin{array}{c}\text { Dispersion } \\
\sigma_{0}^{2}\end{array}$ & $\begin{array}{c}\text { Dispersion } \\
s^{2}\end{array}$ & $\chi_{\operatorname{exper}}^{2}$ & $\begin{array}{c}\text { Dispersion } \\
\sigma_{0}^{2}\end{array}$ & $\begin{array}{c}\text { Dispersion } \\
s^{2}\end{array}$ & $\chi_{\operatorname{exper}}^{2}$ \\
\hline 1 & 17.28 & 1.59 & 21.13 & - & - & - \\
\hline 2 & 1.25 & 1.75 & 40.52 & 96 & 87.66 & 26.48 \\
\hline 3 & 7.14 & 9.38 & 38.10 & 78 & 97.23 & 36.15 \\
\hline 4 & 0.06 & 0.04 & 17.06 & 56 & 66.86 & 34.62 \\
\hline 5 & 7.66 & 6.59 & 24.93 & 183 & 250.90 & 39.76 \\
\hline 6 & 0.53 & 0.36 & 19.67 & 240 & 338.90 & 40.95 \\
\hline
\end{tabular}

Tables 27-29 demonstrate control results of average random sequences of linear voltage harmonics generated with the help of digital generators $(n=30)$.

Table 27

Control results of average harmonics of linear voltage $U_{A B}$

\begin{tabular}{|c|c|c|c|c|c|c|}
\hline \multirow{3}{*}{ Harmonic } & \multicolumn{3}{|c|}{ Amplitude, $\mathrm{V}$} & \multicolumn{3}{c|}{ Phase, degrees } \\
\cline { 2 - 7 } & $\begin{array}{c}\text { Average } \\
a_{0}\end{array}$ & $\begin{array}{c}\text { Average } \\
\text { y }\end{array}$ & $\left|\mathrm{U}_{\text {exper }}\right|$ & $\begin{array}{c}\text { Average } \\
a_{0}\end{array}$ & $\begin{array}{c}\text { Average } \\
\bar{y}\end{array}$ & $\left|\mathrm{U}_{\text {exper }}\right|$ \\
\hline 1 & 529.82 & 531.26 & $|1.8|$ & - & - & - \\
\hline 2 & 4.23 & 4.38 & $|0.7|$ & 63 & 59.95 & $-1.58 \mid$ \\
\hline 3 & 17.60 & 16.85 & -1.35 & 206 & 208.01 & $|1.34|$ \\
\hline 4 & 1.51 & 1.58 & $|1.63|$ & 92 & 94.88 & $|1.71|$ \\
\hline 5 & 18.54 & 17.75 & $-1.51 \mid$ & 130 & 134.99 & $|1.87|$ \\
\hline 6 & 3.05 & 2.95 & $-1.02 \mid$ & 290 & 286.24 & $-1.67 \mid$ \\
\hline
\end{tabular}

Table 28

Control results of average harmonics of linear voltage $\mathbf{U}_{B C}$

\begin{tabular}{|c|c|c|c|c|c|c|}
\hline \multirow{3}{*}{ Harmonic } & \multicolumn{3}{|c|}{ Amplitude, $\mathrm{V}$} & \multicolumn{3}{c|}{ Phase, degrees } \\
\cline { 2 - 8 } & $\begin{array}{c}\text { Average } \\
a_{0}\end{array}$ & $\begin{array}{c}\text { Average } \\
y\end{array}$ & $\left|\mathrm{U}_{\text {exper }}\right|$ & $\begin{array}{c}\text { Average } \\
a_{0}\end{array}$ & $\begin{array}{c}\text { Average } \\
-\end{array}$ & $\mid$\begin{tabular}{|c|}
$\mid$ \\
\end{tabular} \\
\hline 1 & 532.09 & 533.38 & $\mid 1.70$ & - & - & $-1.83 \mid$ \\
\hline 2 & 3.98 & 4.41 & $\mid 1.88$ & 78 & 74.63 & $|1.33|$ \\
\hline 3 & 19.13 & 18.38 & $\mid-1.44$ & 235 & 236.7 & $|-1.85|$ \\
\hline 4 & 1.55 & 1.64 & $\mid 1.92$ & 111 & 114.27 & $|0.97|$ \\
\hline 5 & 16.77 & 17.35 & $\mid 1.25$ & 114 & 109.11 & $\mid$ \\
\hline 6 & 4.15 & 4.33 & $\mid 0.94$ & 325 & 327.08 & $\mid$ \\
\hline
\end{tabular}


Table 29

Control results of average harmonics of linear voltage $U_{C A}$

\begin{tabular}{|c|c|c|c|c|c|c|}
\hline \multirow{3}{*}{ Harmonic } & \multicolumn{3}{|c|}{ Amplitude, $\mathrm{V}$} & \multicolumn{3}{c|}{ Phase, degrees } \\
\cline { 2 - 7 } & $\begin{array}{c}\text { Average } \\
a_{0}\end{array}$ & $\begin{array}{c}\text { Average } \\
\bar{y}\end{array}$ & $\left|\mathrm{U}_{\text {exper }}\right|$ & $\begin{array}{c}\text { Average } \\
a_{0}\end{array}$ & $\begin{array}{c}\text { Average } \\
\bar{y}\end{array}$ & $\left|\mathrm{U}_{\text {exper }}\right|$ \\
\hline 1 & 530.41 & 531.85 & $|1.90|$ & - & - & - \\
\hline 2 & 3.71 & 4.07 & $|1.78|$ & 94 & 91.23 & $|-1.55|$ \\
\hline 3 & 18.27 & 19.09 & $|1.69|$ & 182 & 182.31 & $|0.19|$ \\
\hline 4 & 1.50 & 1.57 & $|1.63|$ & 83 & 85.42 & $|1.77|$ \\
\hline 5 & 16.01 & 16.56 & $\mid 1.08$ & 165 & 169.22 & $|1.71|$ \\
\hline 6 & 3.82 & 3.57 & $\mid-1.88$ & 310 & 315.346 & $|1.89|$ \\
\hline
\end{tabular}

Most of all, the hypothesis, concerning random sampling belonging to the prescribed distribution law, is implemented according to $\chi^{2}$ (i.e. chisquare) Pearson criterion. Idea of the criterion is as follows. Minimum $Y_{\text {min }}$ value as well as maximum $Y_{\max }$ value of random value is determined (i.e. the sample range).

The whole $\left[Y_{\min }, Y_{\max }\right]$ range is divided into intervals which number is identified according to formula ${ }^{14}$ :

$$
m \leq 5 \lg n,
$$

where $\mathrm{n}$ is the sample size.

Then, empiric $h_{i}$ as well as theoretical $n p_{i}=n \int_{Y_{i \min ,}}^{Y_{\text {max }}} f(y) d y$ frequencies is calculated for each $\left[Y_{i \min }, Y_{i \max }\right]$ interval; further, the criterion value is rated $n p_{i}=n \int_{\text {Yimin, }}^{\text {Yimax }} f(y) d y n p_{i}=n \int_{\text {Yimin, }}^{\text {Yimax }} f(y) d y$ :

$$
\chi^{2}=\sum_{i=1}^{m} \frac{\left(h_{i}-n p_{i}\right)^{2}}{n p_{i}} .
$$

Calculations on formula (28) are correct if the theoretical frequencies meet $n p_{i} \geq 5$ inequality requirements. If the inequality requirements cannot be met for certain intervals, they are united with neighbouring ones. The suggested hypothesis concerning random sampling belonging to the prescribed distribution law is accepted for the selected probability of a type 1 error $\alpha$ in the process of engineering problem solving

${ }^{14}$ Borky, J., Bradley, Th.: Effective Model-Based Systems Engineering. 1st ed. 779 p. Springer International Publishing AG. Cham, Switzerland (2019). 
( $\alpha$ significance level is taken as 0.05) if the calculated $\chi^{2} \chi^{2} \chi^{2}$ value is not more than reference value $\chi_{a, k}^{2} \chi_{\alpha, \mathrm{k}}^{2}$. In this context, $k \mathrm{k}$ is the number of degrees of freedom:

$$
k=m-3 .
$$

Tables 30-31 demonstrate check results concerning distribution of random sequences of harmonics of linear voltages produced by digital generators for $n=30 \mathrm{n}=30$ and $\alpha=0.05 \alpha=0,05 \alpha=0,05$ sampling.

Table 30

Check results concerning amplitude distribution laws

\begin{tabular}{|c|c|c|c|c|c|c|c|c|c|}
\hline \multirow{2}{*}{ Harmonic } & \multicolumn{3}{|c|}{ Linear voltage $\mathbf{U}_{\mathbf{A B}}$} & \multicolumn{3}{c|}{ Linear voltage $\mathbf{U}_{\mathbf{B C}}$} & \multicolumn{3}{c|}{ Linear voltage $\mathbf{U}_{\mathbf{C A}}$} \\
\cline { 2 - 10 } & $\chi^{2}$ & $k$ & $\chi_{\alpha, k}^{2}$ & $\chi^{2}$ & $k$ & $\chi_{\alpha, k}^{2}$ & $\chi^{2}$ & $k$ & $\chi_{\alpha, k}^{2}$ \\
\hline 1 & 8.9 & 4 & 9.5 & 7.6 & 3 & 7.8 & 7.3 & 3 & 7.8 \\
\hline 2 & 8.3 & 4 & 9.5 & 9.1 & 4 & 9.5 & 5.5 & 2 & 6.0 \\
\hline 3 & 6.5 & 3 & 7.8 & 7.5 & 3 & 7.8 & 9.0 & 4 & 9.5 \\
\hline 4 & 5.7 & 2 & 6.0 & 7.2 & 3 & 7.8 & 7.1 & 3 & 7.8 \\
\hline 5 & 7.0 & 3 & 7.8 & 5.9 & 2 & 6.0 & 7.7 & 3 & 7.8 \\
\hline 6 & 7.4 & 3 & 7.8 & 6.8 & 3 & 7.8 & 5.4 & 2 & 6.0 \\
\hline
\end{tabular}

Table 31

Check results concerning phase distribution laws.

\begin{tabular}{|c|c|c|c|c|c|c|c|c|c|}
\hline \multirow{2}{*}{ Harmonic } & \multicolumn{3}{|c|}{ Linear voltage $\mathbf{U}_{\mathbf{A B}}$} & \multicolumn{3}{c|}{ Linear voltage $\mathbf{U}_{\mathbf{B C}}$} & \multicolumn{3}{c|}{ Linear voltage $\mathbf{U}_{\mathbf{C A}}$} \\
\cline { 2 - 11 } & $\chi^{2}$ & $k$ & $\chi_{\alpha, k}^{2}$ & $\chi^{2}$ & $k$ & $\chi_{\alpha, k}^{2}$ & $\chi^{2}$ & $k$ & $\chi_{\alpha, k}^{2}$ \\
\hline 1 & 7.5 & 3 & 7.8 & 7.7 & 3 & 7.8 & 7.6 & 3 & 7.8 \\
\hline 2 & 7.6 & 3 & 7.8 & 7.6 & 3 & 7.8 & 5.7 & 2 & 6.0 \\
\hline 3 & 5.9 & 2 & 6.0 & 9.3 & 4 & 9.5 & 5.8 & 2 & 6.0 \\
\hline 4 & 7.6 & 3 & 7.8 & 5.4 & 2 & 6.0 & 7.4 & 3 & 7.8 \\
\hline 5 & 5.8 & 2 & 6.0 & 7.5 & 3 & 7.8 & 8.8 & 4 & 9.5 \\
\hline 6 & 5.9 & 2 & 6.0 & 7.5 & 3 & 7.8 & 5.9 & 2 & 6.0 \\
\hline
\end{tabular}

As it follows from Tables 24-31, numerical characteristics of harmonics of linear voltages, being generated for rolling plant 1 of Dneprospetsstal OJSC (Zaporozhie) differ insignificantly from hypothetic ones; thus, the digital model, set for the considered conditions, can be regarded as adequate one.

\section{CONCLUSIONS}

It is practical to carry out studies, concerning electric equipment efficiency within power grids with noisy electricity, basing upon 
computational experiments with the use of linear voltage generators developed on the basis of a method of statistical tests.

Since all harmonic components of linear voltages within power grids with noisy electricity have fixed oscillation frequencies, on which changes in amplitudes and initial phases are just superimposed, their modeling by means of statistical methods is expedient while generating random sequences of the latter.

Availability of large intervals between random switching on/switching off of electrical equipment within power grids results in nonstationarity of linear voltages which involves separation of stationary sections.

While using switching on/switching off of equipment, event numbers as an argument of random functions of linear voltages, studies of statistical regularities of linear voltages within workshop power grid can be carried out as part of correlation analysis.

Randomization of computational sequences of harmonics of linear voltages helps decrease systematic modeling error.

Use of the developed probability model of a workshop power grid with noisy electrical energy helps making correct engineering solutions to provide the prescribed functioning conditions for asynchronous motors basing upon computational studies.

\section{SUMMARY}

The Monograph section is proposes the generator of random voltage changes in electrical networks of enterprises that implements the relationship of the energy - economic model of an asynchronous motor with the external environment. When reproducing voltages on a computer, the amplitudes and phases of significant harmonics, their distribution laws, autocorrelation and cross-correlation functions are taken into account. The formation of voltages from individual harmonics is shown. The statistical regularities of harmonics are obtained as a result of processing the changes in voltages obtained during passive industrial experiments for the conditions of Dneprospetsstal LLC. Analytical expressions for the autocorrelation and cross-correlation functions of harmonics are obtained from individual reference points at which the experimental values and the values calculated from the approximating expression coincide. To implement the obtained static laws on a computer, their digital models and a modeling algorithm have been developed. The simulation results are checked for adequacy to the real process. 


\section{REFERENCES}

1. Строгалев В.П. Имитационное моделирование : учеб. пособие. Москва : Изд-во МГТУ им. Н.Э. Баумана, 2008. 280 с.

2. Качан Ю.Г. О моделировании напряжений в электрических сетях промышленных предприятий. Електротехніка $i$ електроенергетика. № 1. 2012. С. 72-75.

3. M. Tryputen, V. Kuznetsov, A. Kuznetsova, K. Maksim and M. Tryputen, Developing Stochastic Model of a Workshop Power Grid, 2020 IEEE Problems of Automated Electrodrive. Theory and Practice (PAEP), Kremenchuk, Ukraine, 2020, pp. 1-6, doi: 10.1109/ PAEP49887.2020.9240898.

4. Прохоров С.А. Математическое описание и моделирование случайных процессов. Уральск : Самар. гос. аэрокосм. ун-т, 2001. 209 c.

5. Yaglom, A.M. Correlation Theory of Stationary and Related Random Functions : Supplementary Notes and References. (Springer Series in Statistics). Softcover reprint of the original 1st ed. 1987 edition. 287 p., Springer, New York; (October 13, 2011).

6. Бендат Дж. Прикладной анализ случайных данных. Москва : Мир, 1989. 540 с.

7. Kuznetsov Vitaliy, Tryputen Nikolay, Kuznetsova Yevheniia "Evaluating the Effect of Electric Power Quality upon the Efficiency of Electric Power Consumption", 2019 IEEE 2nd Ukraine Conference on Electrical and Computer Engineering (UKRCON), Lviv, Ukraine, 2019, pp. 556-561, doi: 10.1109/UKRCON.2019.8879841.

8. Кобзарь А.И. Прикладная математическая статистика. Москва : Физматлит, 2006. 238 с.

9. Hastie, T., Tibshirani, R., Friedman, J.: The Elements of Statistical Learning: Data Mining, Inference, and Prediction, Second Edition. 745 p., Springer Science+Business Media, Ney York, USA (2017).

10. Гмурман В.Е. Руководство к решению задач по теории вероятности и математической статистике : учеб. пособие для студентов вузов. Москва : Высш. шк., 2004. 404 с.

11. Papoulis and S. U. Pillai, Probability, Random Variables and Stochastic Processes. New York : McGraw-Hill, 2001.

12. Kendall, M., Gibbons, J.: Rank Correlation Methods. 260 pp. 5th edn., Edward Arnold, London, (1990) Kendall, M., Gibbons, J.: Rank Correlation Methods. 260 pp. 5th edn., Edward Arnold, London, (1990). 
13. Bonett, Douglas G.; Wright, Thomas A. (2000). Sample size requirements for estimating Pearson, Kendall, and Spearman correlations. Psychometrika. 65 (1): 23-28.

14. Borky , J., Bradley, Th.: Effective Model-Based Systems Engineering. 1st ed. 779 p. Springer International Publishing AG. Cham, Switzerland (2019).

\section{Information about authors:} Kuznetsov V. V.,

Candidate of Technical Sciences, Associate Professor at the Department of the Electrical Engineering and Electromechanic National Metallurgical Academy of Ukraine 4, Gagarin avenue, Dnipro, 49000, Ukraine

Tryputen M. M.,

Candidate of Technical Sciences, Associate Professor at the Department of Cyberphysical and Information-Measuring Systems National Technical University Dnipro Polytechnic 19, Dmytro Yavornytskoho avenue, Dnipro, 49000, Ukraine 